\title{
Synthesis and Characterization of a Novel Series of Meso (Nitrophenyl) and Meso (CarboxyPhenyl) Substituted Porphyrins
}

\author{
Marco A. Schiavon ${ }^{a}$, Lidia S. Iwamoto $^{\dagger}{ }^{a}$, Antônio G. Ferreira ${ }^{b}$, \\ Yassuko Iamamoto ${ }^{a}$, Maria V. B. Zanoni and Marilda das D. Assis ${ }^{{ }^{*}}$ \\ ${ }^{\mathrm{a}}$ Departamento de Química, Faculdade de Filosofia, Ciências e Letras de Ribeirão Preto, \\ Universidade de São Paulo, Av. Bandeirantes, 3900, 14040-901, Ribeirão Preto - SP, Brazil. \\ ${ }^{b}$ Departamento de Química, Universidade Federal de São Carlos, \\ Rodovia Washington Luis Km 235, 13595-905, São Carlos - SP, Brazil. \\ ${ }^{\mathrm{c}}$ Instituto de Química, Universidade Estadual Paulista, CP 355, 14801-970, Araraquara - SP, Brazil
}

As porfirinas aniônicas 5,10,15-tris(4-carboxifenil), 20-mono(2-nitrofenil) porfirina (1), 5,10(ou 15)-bis(4-carboxifenil), 15(or 10),20-bis(2-nitrofenil)porfirina (2) and 5-mono(4-carboxifenil), 10,15,20tris(2-nitrofenil)porfirina (3), foram sintetizadas diretamente através da reação de pirrol com os benzaldeídos substituídos em meio de ácido propiônico/nitrobenzeno. A relação molar dos benzaldeídos foi controlada para otimizar a síntese e purificação das porfirinas desejadas. Esta nova série de porfirinas foi caracterizada por cromatografia em camada delgada, espectrometria de massas (FAB MS), RMN ${ }^{1} \mathrm{H}$, UV/Vis, IV e eletroquímica. As porfirinas 5,10,15,20-tetrakis(4-carboxifenil)porfirina (4) e 5,10,15,20-tetrakis(2-nitrofenil)porfirina (5) também foram estudadas para comparação, tornando a série completa. A redução eletroquímica das porfirinas base livre e correspondentes ferro(III) porfirinas foi investigada em eletrodos de carbono e mercúrio. Os potenciais de redução mostraram a dependência esperada do número de grupos nitro, fortemente retirador de elétrons, presentes no anel porfirínico, fornecendo evidências adicionais para a caracterização dos compostos sintetizados.

The anionic 5,10,15-tris(4-carboxyphenyl), 20-mono(2-nitrophenyl) porphyrin (1), 5,10(or 15)bis(4-carboxyphenyl), 15(or 10),20-bis(2-nitrophenyl)porphyrin (2) and 5-mono(4-carboxyphenyl), 10,15,20-tris(2-nitrophenyl)porphyrin (3) were sinthesized directly by reaction of pyrrole with substituted benzaldehydes in nitrobenzene/propionic acid media. The benzaldehydes molar ratio was controlled to optimize the synthesis and purification of the desired porphyrins. This new series of porphyrins was characterised by TLC, mass spectrometry (FAB MS), ${ }^{1} \mathrm{H}$ NMR, UV/Vis, IR and electrochemistry. 5,10,15,20-Tetrakis(4-carboxyphenyl)porphyrin (4) and 5,10,15,20-Tetrakis(2nitrophenyl)porphyrin (5) were also characterised for comparative purposes, completing the series The electrochemical reduction was investigated for the free base and corresponding iron(III) porphyrins on glassy carbon and mercury electrodes. The reduction potentials showed the expected dependence on the number of electron-withdrawing nitro groups present on the porphyrin ring providing additional evidences for the characterisation of the synthesised compounds.

Keywords: anionic porphyrins, synthesis of porphyrins, metalloporphyrins, electrochemistry of porphyrins

\section{Introduction}

The synthesis of porphyrins has gained special attention in recent years because of their importance in bioorganic and bioinorganic chemistry ${ }^{1}$ and their applications in biomedical sciences. Porphyrins are used, for example, to

\footnotetext{
*e-mail: mddassis@usp.br
}

+ in memoriam mimic the function of hemeproteins such as cytochrome $\mathrm{P}$ 450 in oxidation catalysis ${ }^{2}$, as photosensitizers in photodynamic therapy of cancer (PDT) ${ }^{3}$, in electron transport chains ${ }^{4}$ and as building blocks in molecular devices ${ }^{5}$. Each research area requires porphyrins with different and specific structural features, bearing a variety of different substituents.

Carboxy substituted porphyrins are attractive synthetic targets for three reasons: firstly, these substituents are present in natural porphyrins such as protoporphyrin IX, the 
prosthetic group of many important biological molecules like hemoglobin ${ }^{6}$. Secondly, the carboxy group confers an amphyphylic character to the porphyrins, and this is very important, for example, to improve the selectivity in tumour localization in PDT $^{3}$. Lastly, carboxy groups can act as linkers to attach porphyrins to other materials, for example, they can be anchored to solid supports by amidation ${ }^{7}$.

We are interested in meso-para-carboxy and mesoortho-nitro phenyl substituted porphyrins. The carboxy groups when ionised provide the charges necessary to enable their intercalation into lamellar double hydroxides $(\mathrm{LDH})^{8}$ or to support them on cationic functionalized silicas through electrostatic binding. They can also be covalently linked to amino-functionalized silica to give heterogeneous porphyrin catalysts ${ }^{7}$. The ortho-nitro groups are important, since they remove electron density from the porphyrin ring and provide steric hindrance improving the stability of the metalloporphyrin catalysts in oxidation reactions ${ }^{9}$. The nitro group can improve the ability of porphyrin systems to act as radiosensitizers ${ }^{10}$ and, like carboxy groups, they can act as linkers to attach porphyrins to other materials?

The purpose the present study was to combine the advantages offered by both functional groups into one porphyrin ligand. The corresponding metalloporphyrins will be used as catalysts for hydrocarbon oxidations in homogeneous and supported systems.

In this paper, we report the synthesis and purification of anionic tetraarylporphyrins bearing carboxy- and nitrosubstituents on the phenyl rings (Figure 1), using the method of Gonsalves et al ${ }^{11}$. The characterisation of water-soluble porphyrins is much more difficult than the characterisation of porphyrin derivatives soluble in organic solvents because of their salt-like character. UV/Vis and ${ }^{1} \mathrm{H}$ NMR spectra are severely complicated by aggregation effects and a quantitative interpretation is rarely possible. The results of elemental analyses are not definitive because the substances are strongly hygroscopic ${ }^{12}$. Therefore, the synthesized porphyrins were characterised by combining thin layer chromato-graphy (TLC), mass spectrometry (FAB MS), ${ }^{1} \mathrm{H}$ NMR, UV/Vis and IR spectroscopies and electrochemistry and by comparison with the commercial tetra-(para-carboxyphenyl) and tetra-(ortho-nitrophenyl) porphyrins.

\section{Experimental}

\section{Materials and methods}

Commercially available chemicals and solvents were from Aldrich, Fisons, Sigma and Merck, unless otherwise stated. Silica gel (230-400 mesh) was purchased from Merck

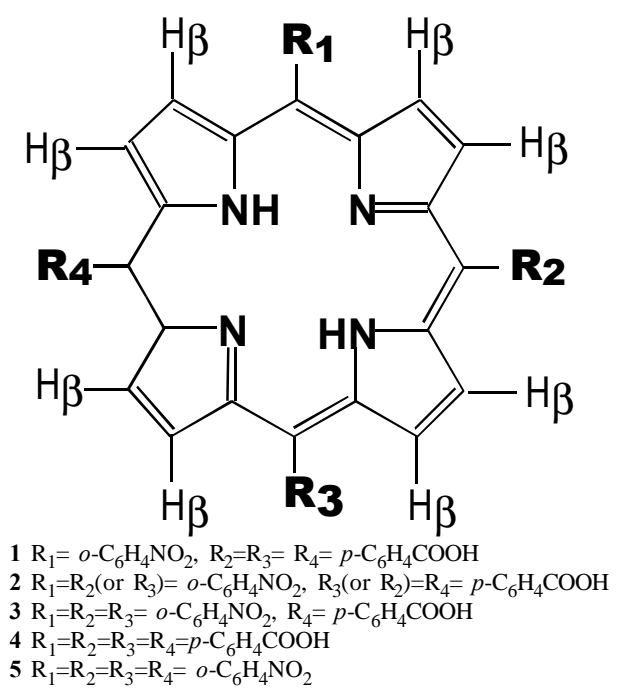

Figure 1. Nitro and carboxy substituted porphyrins

and Florisil (magnesia silicate 60-100 mesh) from J.T. Baker. 5,10,15,20-Tetrakis(4-carboxyphenyl)porphyrin (4) and 5,10,15,20- tetrakis(2-nitrophenyl)porphyrin (5) and 5,10,15,20-tetraphenylporphyrin (6) were purchased from Midcentury and used as received.

UV/Vis spectra were recorded on a Hewlett Packard 8452 Diode Array spectrophotometer. The spectra were recorded in $2 \mathrm{~mm}$ path length quartz cells (Hellma). The FTIR spectra were recorded on a FT spectrometer-BOMEN $\mathrm{B}-100\left(4000-400 \mathrm{~cm}^{-1}\right)$ in $\mathrm{KBr}$ pellets; the $\mathrm{FeP}: \mathrm{KBr}$ molar ratio was aproximately 1:2000. FAB mass spectra were recorded on a V.G. Analytical Autospec Instrument, using $\mathrm{FAB}^{+}$mode. 4-Nitrobenzyl alcohol was used as the matrix and caesium ion bombardment to generate the ions. The ${ }^{1} \mathrm{H}$ NMR measurements were recorded on a BRUKER $400.13 \mathrm{MHz}$, DRX400 spectrometer operating at $303 \mathrm{~K}$ using a $5 \mathrm{~mm}$ BBO probe with temperature control. The ${ }^{1} \mathrm{H}$ NMR spectra of $\mathbf{2}, \mathbf{3}$ and $\mathbf{5}$ were obtained in $\mathrm{CD}_{2} \mathrm{Cl}_{2}$ solution $\left(2,5 \times 10^{-2} \mathrm{~mol} \mathrm{dm}^{-3}\right)$ and for 1 and $4 \mathrm{CD}_{3} \mathrm{OD}$ solutions of the same concentration were used. All spectra were acquired with spectral widths of approximately 16000 $\mathrm{Hz}$ and $64 \mathrm{~K}$ data points for acquisition using TMS as internal reference. All electrochemical experiments were carried out with a Metrohm Polarecord E-506 coupled to a Metrohm 663 VA Stand which was connected to a computer for data storage and handling. A multimode electrode system was used in both the dropping mercury electrode for differential pulse polarographic measurements and the glassy carbon electrode for cyclic voltammetric measurements. The glassy carbon electrode was polished with alumina before each experiment, rinsed with water, cleaned in a ultrasound bath and dried at room temperature. The three-electrode system was completed with a glassy 
carbon auxiliary electrode and an $\mathrm{Ag} / \mathrm{AgCl}\left(3 \mathrm{~mol} \mathrm{dm}^{-3}\right.$ $\mathrm{KCl}$ ) reference electrode. A pulse amplitude of $50 \mathrm{mV}$ was used for differential pulse polarography. Tetra-n-butylammonium tetraphenylborate (TBATFB) was obtained from Eastman Chemicals and was used as received. Porphyrin solutions were $1 \times 10^{-4} \mathrm{~mol} \mathrm{dm}^{-3}$, prepared by dissolving the purified substance in $\mathrm{CH}_{2} \mathrm{Cl}_{2}$.

\section{Synthesis and purification of porphyrins} and metalloporphyrins

5,10,15-Tris(4-carboxyphenyl)20-mono(2-nitrophenyl) porphyrin (1), 5,10(or 15)-bis(4-carboxyphe-nyl)15(or 10),20bis(2-nitrophenyl) porphyrin (cis- or trans-isomer) (2) and 5mono(4-carboxyphenyl)10,15,20-tris(2-nitrophenyl) porphyrin (3) were prepared according to the method of Gonsalves $e a^{11}$. The procedure was repeated with different ratios of 2-nitrobenzaldehyde to 4-carboxybenzaldehyde in order to optimize the yields of the desired porphyrin.

\section{Synthesis of $\mathbf{1}$}

2-Nitrobenzaldehyde (1.47 g, $9.8 \mathrm{mmol})$ and 4carboxybenzaldehyde $(3.04 \mathrm{~g}, 20.2 \mathrm{mmol})$ were mixed with propionic acid $\left(105 \mathrm{~cm}^{3}\right)$ and nitrobenzene $\left(45 \mathrm{~cm}^{3}\right)$ and pyrrole $\left(2.08 \mathrm{~cm}^{3}, 30 \mathrm{mmol}\right)$ was added. The reaction vessel was shielded from ambient light and the mixture was heated at $120^{\circ} \mathrm{C}$ for $1 \mathrm{~h}$. After cooling and solvent removal under vacuum the crude porphyrin was adsorbed onto $10.5 \mathrm{~g}$ of Florisil. This mixture was applied to a dry-packed Florisil column and eluted with solvents of increasing polarity: dichloromethane, dichloromethane/methanol ( $9: 1)$, dichloromethane/methanol $(1: 1)$, and methanol. The last two fractions which contained porphyrins $\mathbf{1}$ and 2, were filtered to eliminate the Florisil particles. The solvent was removed under vacuum and the solid porphyrins were finally purified by column chromatography on silica with dichloromethane/acetone/acetic acid $(8: 2: 0.1)$ as eluent to give $297 \mathrm{mg}\left(3.75 \times 10^{-4} \mathrm{~mol}, 5 \%\right.$ yield) of pure $1, \lambda_{\max } / \mathrm{nm}\left(\mathrm{CH}_{3} \mathrm{OH}\right) 416\left(\varepsilon / \mathrm{dm}^{3} \mathrm{~mol}^{-1} \mathrm{~cm}^{-1} 2.3\right.$ x $\left.10^{5}\right), 514\left(1.3 \times 10^{4}\right), 546\left(6.9 \times 10^{3}\right), 590\left(5.7 \times 10^{3}\right), 644$ $\left(3.7 \times 10^{3}\right) ; m / z\left(\mathrm{M}^{+}\right) 792$.

\section{Synthesis of $\mathbf{2}$}

This compound was obtained as a by-product from the syntheses of $\mathbf{1}$ and $\mathbf{3}, \lambda_{\max } / \mathrm{nm}\left(\mathrm{CH}_{3} \mathrm{OH}\right) 416\left(\varepsilon / \mathrm{dm}^{3} \mathrm{~mol}^{-1}\right.$ $\left.\mathrm{cm}^{-1} 2.1 \times 10^{5}\right), 514\left(1.3 \times 10^{4}\right), 548\left(5.5 \times 10^{3}\right), 590$ $\left(4.0 \times 10^{3}\right), 648\left(2.2 \times 10^{3}\right) ; \mathrm{m} / z\left(\mathrm{M}^{+}\right) 793$.

\section{Synthesis of $\mathbf{3}$}

2-Nitrobenzaldehyde (1.81 g, $12 \mathrm{mmol})$ and 4-carboxybenzaldehyde ( $0.45 \mathrm{~g}, 3 \mathrm{mmol}$ ) were mixed with propionic acid $\left(52.5 \mathrm{~cm}^{3}\right)$ and nitrobenzene $\left(22.5 \mathrm{~cm}^{3}\right)$ and pyrrole $\left(1.04 \mathrm{~cm}^{3}, 15 \mathrm{mmol}\right)$ was added. The reaction and purification were similar for 1 giving $148 \mathrm{mg}\left(1.86 \times 10^{-4}\right.$ mol, $5 \%$ yield) of pure $3, \lambda_{\max } / \mathrm{nm}\left(\mathrm{CH}_{3} \mathrm{OH}\right) 418$ $\left(\varepsilon / \mathrm{dm}^{3} \mathrm{~mol}^{-1} \mathrm{~cm}^{-1} 1.0 \times 10^{5}\right), 514\left(8.7 \times 10^{3}\right), 550(4.6 \mathrm{x}$ $\left.10^{3}\right), 590\left(4.0 \times 10^{3}\right), 650\left(1.9 \times 10^{3}\right) ; \mathrm{m} / z\left(\mathrm{M}^{+}\right) 794$.

Synthesis of iron(III)porphyrins, FeP (1-Fe, 2-Fe, 3-Fe, 4-Fe, 5-Fe)

These compounds were prepared by refluxing the free base porphyrins (amounts corresponding to $0.2 \mathrm{mmol}$ ) with iron(II) chloride tetrahydrate (amount corresponding to 2 mmol) in N,N'-dimethylformamide $\left(15 \mathrm{~cm}^{3}\right)$ under nitrogen by the method of Adler $e t \mathrm{al}^{13}$. The reaction was monitored by UV/Vis spectroscopy and TLC. The iron porphyrins were precipitated from the reaction medium by adding $\mathrm{HCl} 0.10$ mol dm${ }^{-3}\left(15 \mathrm{~cm}^{3}\right)$, and cooling the reaction flask in an ice bath. The precipitates were recovered by centrifugation and the supernatant, which contained DMF and excess iron(II) salt, was discarded. The iron porphyrins were washed with $\mathrm{HCl} 0.10 \mathrm{~mol} \mathrm{dm}^{-3}\left(30 \mathrm{~cm}^{3}\right)$ and purified by silica column chromatography. The solvents used to elute firstly the free base porphyrin followed by the iron porphyrins were: methanol and methanol/acetic acid mixture (10:0.1) for 1Fe; a dichloromethane/acetone/acetic acid mixture $(8: 2$ : $0,1)$ for $\mathbf{2}-\mathbf{F e}$; dichloromethane and a dichloromethane/ methanol mixture (9:1) for 3-Fe. These procedures gave the amounts corresponding to metallation yields of 1-Fe - 64\%; $\lambda_{\max } / \mathrm{nm}\left(\mathrm{CH}_{3} \mathrm{OH}\right) 338\left(\varepsilon / \mathrm{dm}^{3} \mathrm{~mol}^{-1} \mathrm{~cm}^{-1} 2.2 \times 10^{4}\right), 416$ $\left(6.2 \times 10^{4}\right), 582\left(3.5 \times 10^{3}\right), 656$ (shoulder). $\mathrm{m} / z\left(\mathrm{M}^{+}\right): 845.2$ Fe - 55\%; $\lambda_{\text {max }} / \mathrm{nm}$ (dichloroethane) $372\left(\varepsilon / \mathrm{dm}^{3} \mathrm{~mol}^{-1} \mathrm{~cm}^{-1}\right.$ $\left.3.2 \times 10^{4}\right), 422\left(6.2 \times 10^{4}\right), 510\left(1.0 \times 10^{4}\right), 582\left(4.5 \times 10^{3}\right)$, 670 (broad, $\left.3 \times 10^{3}\right) . \mathrm{m} / z\left(\mathrm{M}^{+}\right): 846 ; 3-\mathrm{Fe}-72 \% ; \lambda_{\max } / \mathrm{nm}$ (dichloroethane) $368\left(\varepsilon / \mathrm{dm}^{3} \mathrm{~mol}^{-1} \mathrm{~cm}^{-1} 3.8 \times 10^{4}\right), 422$ $\left(7.2 \times 10^{4}\right), 510\left(1.1 \times 10^{4}\right), 582\left(5.4 \times 10^{3}\right) ; \mathrm{m} / z\left(\mathrm{M}^{+}\right) 847$.

\section{Results and Discussion}

\section{Porphyrins syntheses}

The greatest advance in the development of methods for porphyrin synthesis since the classic Rothemund process $^{14}$ has been the procedure of Lindsey et $\mathrm{al}^{15}$. The gentle conditions of this synthesis provide means for converting a large range of pre-functionalized benzaldehydes into the corresponding porphyrins. For this reason, the method has been widely employed over recent years. However, Lindsey's method fails when the porphyrin synthesis involves benzaldehydes bearing ionic substituents which are insoluble in the reaction solvents dichloromethane 
or chloroform, unless the ionic group is masked. In this way, the synthesis of porphyrins bearing carboxy groups often requires the acid groups to be masked as esters. This consequently involves an extra step of group deprotection after the porphyrin has been formed ${ }^{16}$. We decided to use the method of Gonsalves et $a l^{11}$, which employs propionic acid and nitrobenzene medium, in the synthesis of the orthonitrophenyl and para-carboxyphenyl substituted porphyrin series. Whereas in Lindsey's method an expensive highly potent quinone is used as the oxidant, in the method of Gonsalves the oxidant is the nitrobenzene/propionic acid solvent. The latter also leads to the precipitation of the porphyrin from the reaction medium, thus facilitating its isolation and purification.

A mixed aldehyde condensation using stoichiometric amounts of ortho-substituted benzaldehyde (A), parasubstituted benzaldehyde (B) and pyrrole affords a mixture of six different porphyrins which can be separated chromatographically ${ }^{5 \mathrm{a}}$. In order to decrease the number of porphyrins obtained in the synthesis and to avoid extremely tedious chromatographic purification processes the system was optimized with small scale reactions using different ratios of the two aldehydes. In this way each of the porphyrins $\mathrm{A}_{3} \mathrm{~B}, \mathrm{~A}_{2} \mathrm{~B}_{2}$ (cis and trans) and $\mathrm{AB}_{3}$ were prepared.

In the synthesis of $\mathbf{1}\left(\mathrm{AB}_{3}\right)$ porphyrin, the initial ratio of pyrrole:ortho-nitrobenzaldehyde:para-carboxybenzaldehyde used was 4:0.8:3.2, rather than the stoichiometric 4:1:3 ratio. This synthesis gave a crude yield of $36 \%$ (estimated by the absorption of the Soret band in the UV/ Vis spectrum of the reaction mixture) of the two porphyrins $\mathbf{4}$ and $\mathbf{1}$ at a 13:1 ratio as determined through the mass of porphyrins after purification. In a second experiment, taking into consideration the higher reactivity of paracarboxybenzaldehyde, the relative amount of orthonitrobenzaldehyde was increased and the reagents ratio used was 4:1.6:2.4. This synthesis led to a high crude yield ( $60 \%$ estimated by UV/Vis) of the mixture of the three porphyrins $\mathbf{1}, \mathbf{2}$ and $\mathbf{3}$. In a third experiment, the relative amounts of the two benzaldehydes $(4: 1.3: 2.7)$ were fitted to obtain a high crude porphyrin yield $(60 \%$, estimated by $\mathrm{UV} / \mathrm{Vis}$ ) corresponding to the mixture of $\mathbf{1}$ and $\mathbf{2}$. This was the optimized condition used to obtain $\mathbf{1}$. The final yield of $\mathbf{1}$ after purification was $5 \%$, based on pyrrole.

To synthesize the $\left(\mathrm{A}_{3} \mathrm{~B}\right)$ porphyrin $\mathbf{3}$, we used pyrrole : $o$-nitrobenzaldehyde : $p$-carboxybenzaldehyde at a molar ratio of $4: 3.2: 0.8$. In this synthesis, the porphyrins $\mathbf{5}, \mathbf{3}$ and $\mathbf{2}$ were detected and the desired porphyrin $\mathbf{3}$ was obtained in 5\% yield based on the starting pyrrole, after purification. Such yields are good, considering the losses in purification and if compared to other similar preparations involving mixed substituents ${ }^{3 b, 3 c, 17,18}$.
For porphyrins purification, a careful study of the total polarity of the eluent to be employed was necessary. This study was carried out using TLC on silica gel and the ternary solvent mixtures initially used, such as benzene/ methanol/acetic acid, water/acetonitrile/p-dioxane or 2,6lutidine/water/ammonia (gas) described in the literature for natural and synthetic systems containing different numbers of carboxylic groups ${ }^{19}$. However, these water/ solvent mixtures were not effective in the present study. Winkelman's ${ }^{20}$ quaternary solvent system, pyridine/ chloroform/water/acetic acid (2:1:1:1) employed for the separation of porphyrins containing different numbers of $\mathrm{SO}_{3} \mathrm{H}$ groups, obtained from the sulfonation of 4 , was also ineffective for separating the $o$-nitro- and $p$-carboxysubstituted porphyrins. Finally, by using the ternary solvent mixture, chloroform/acetone/acetic acid $(8: 2$ : $0,1)$ proposed by Harada et $a l^{21}$ for the separation of the meso-mono-( $p$-carboxyphenyl)tri-phenylporphyrin from the mixture of this porphyrin and meso-tetraphenylporphyrin, good separations were obtained. By substituting chloroform for dichloromethane, we obtained the ideal solvent mixture for the purification of the porphyrins to be studied. Porphyrins $\mathbf{4}$ and $\mathbf{5}$ were also analysed in this solvent mixture as references. A difference of $0.10-0.20$ in the $\mathrm{Rf}$ values per added carboxy group was observed (see Table I), with the exception of $\mathbf{4}$, which did not elute from the origin. The fraction containing $\mathbf{2}$ was probably a mixture of the cis and trans isomers. However it was not possible to separate them under the conditions used.

Table 1. $\mathrm{R}_{\mathrm{f}}$ values obtained by silica gel TLC for ortho-nitro and para-carboxy-substituted porphyrins, $(\mathrm{P}) \mathrm{H}_{2}$, and iron(III) porphyrins $(\mathrm{FeP})$. Eluent: dichloromethane: acetone: acetic acid $(8: 2: 0.1)$.

\begin{tabular}{ccc}
\hline Porphyrin & $\mathrm{R}_{\mathrm{f}}$ & \\
\hline & $(\mathrm{P}) \mathrm{H}_{2}$ & $\mathrm{FeP}$ \\
\hline $\mathbf{5}$ & 0.84 & 0.84 \\
$\mathbf{3}$ & 0.68 & 0.62 \\
$\mathbf{2}$ & 0.49 & 0.44 \\
$\mathbf{1}$ & 0.37 & 0.28 \\
$\mathbf{4}$ & 0 & 0.10 \\
\hline
\end{tabular}

In conclusion the mixed ortho-nitrophenyl and paracarboxyphenyl substituted porphyrins can be obtained directly by the Gonsalves method. Furthermore, by controlling the molar ratio of the benzaldehydes, it is possible to optimize the synthesis and purification of the desired porphyrins.

\section{Infrared spectroscopy}

Infrared spectroscopy was very useful for the characterisation of the studied porphyrin series, due to the 
presence of the $\mathrm{NO}_{2}$ and $\mathrm{COOH}$ substituents, whose absorption bands are defined and easy to assign.

Compounds containing the $\mathrm{NO}_{2}$ group have strong absorption bands from symmetric and asymmetric deformations (1389- $1259 \mathrm{~cm}^{-1}$ and $1661-1499 \mathrm{~cm}^{-1}$, respectively) ${ }^{22}$. The exact position of these bands depends on the substitutions and unsaturations within the $\mathrm{NO}_{2}$ group. Collman et al ${ }^{23}$ assigned the $1542-1526 \mathrm{~cm}^{-1}$ and $1356-1340 \mathrm{~cm}^{-1}$ absorption ranges to the asymmetrical and symmetrical vibrations, respectively, for the $\mathrm{NO}_{2}$ groups in 5,10,15,20-tetrakis-(o-nitrophenyl)porphyrin), 5. Goldberg et al ${ }^{24}$ reported these absorptions at 1500 and $1330 \mathrm{~cm}^{-1}$, respectively, for the same porphyrin. Table 2 shows the absorption frequencies observed for these groups on the porphyrins synthesized in this study. The values for $\mathbf{4}$ and $\mathbf{5}$ are also included for comparison purposes.

Porphyrins containing $\mathrm{NO}_{2}$ groups as substituents on the meso-phenyl rings (Table 2) show the characteristic absorption bands of this group which agree with Collman's results $^{23}$. The relative absorption intensities decrease in the order $5,3, \mathbf{2}$ and $\mathbf{1}$, as would be expected upon decreasing the number of $\mathrm{NO}_{2}$ groups in these porphyrins (Figure 2).

Table 2. Main infrared absorption frequencies corresponding to the nitro and carboxy groups in the meso-substituted porphyrins.

\begin{tabular}{lccccc}
\hline Porphyrin & $v \mathrm{C}=\mathrm{O}$ & $v \mathrm{C}-\mathrm{O}$ & $v \mathrm{C}-\mathrm{O}$ & $v_{\text {ass }} \mathrm{NO}_{2}$ & $v_{\text {sym }} \mathrm{NO}_{2}$ \\
\hline $\mathbf{5}$ & - & - & - & $1525(\mathrm{vs})$ & $1348(\mathrm{~s})$ \\
$\mathbf{3}$ & $1694(\mathrm{~s})$ & $1405(\mathrm{w})$ & $1282(\mathrm{w})$ & $1525(\mathrm{vs})$ & $1348(\mathrm{~s})$ \\
$\mathbf{2}$ & $1692(\mathrm{~s})$ & $1402(\mathrm{~m})$ & $1276(\mathrm{~m})$ & $1526(\mathrm{vs})$ & $1347(\mathrm{~s})$ \\
$\mathbf{1}$ & $1693(\mathrm{vs})$ & $1403(\mathrm{~m})$ & $1268(\mathrm{~s})$ & $1527(\mathrm{~s})$ & $1348(\mathrm{~m})$ \\
$\mathbf{4}$ & $1692(\mathrm{vs})$ & $1402(\mathrm{~s})$ & $1268(\mathrm{vs})$ & - & - \\
\hline
\end{tabular}

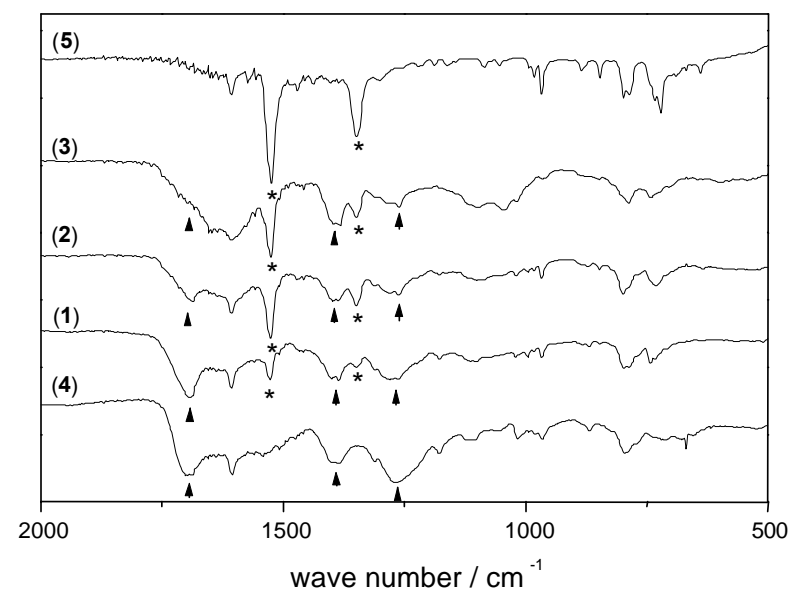

Figure 2. FTIR spectra of porphyrins with $\mathrm{NO}_{2}$ and $\mathrm{COOH}$ substituents in $\mathrm{KBr}$ pellets. Bands marked with * correspond to $\mathrm{NO}_{2}$ vibration and bands marked with $\boldsymbol{\Delta}$ correspond to the $\mathrm{COOH}$ group.

The carboxylic acids are well assigned in FTIR spectroscopy to regions near 1700,1400 and $1250 \mathrm{~cm}^{-1}$ of the spectrum ${ }^{22}$ and the study of all these regions provide a reliable identification of these acids. The absorption near $1700 \mathrm{~cm}^{-1}$ is assigned to $\mathrm{C}=\mathrm{O}$ stretching vibration. Carboxylic acids are capable of forming hydrogen bonds between the carbonyl and hydroxyl groups of the two molecules and this carbonyl frequency is accordingly reduced $^{25}$. In this study, the porphyrins bearing carboxy substituents show carbonyl frequencies near $1690 \mathrm{~cm}^{-1}$ (Table 2 and Figure 2) indicating aggregation through hydrogen bonds.

The two other absorptions, near $1400 \mathrm{~cm}^{-1}(1440$ $\left.1395 \mathrm{~cm}^{-1}\right)$ and near $1250 \mathrm{~cm}^{-1}\left(1320-1210 \mathrm{~cm}^{-1}\right)$ have been associated by many workers to the single bond C-O stretching vibration ${ }^{25}$. These bands appear in the spectrum of 4 as very intense and large bands centred at 1402 and $1268 \mathrm{~cm}^{-1}$, which agree with data reported by Datta-Gupta and Bardos for this free-base porphyrin ${ }^{16}$. The intensity of these bands decreases in the order: $\mathbf{4}>\mathbf{1}>\mathbf{2}>\mathbf{3}$, as expected, due to the decrease in the number of carboxylic acid groups in these porphyrins (Figure 2).

The others bands, not assigned here, are atributed to the vibration of the ring porphyrinic and phenyls group meso-substituents, and are well established in the literature ${ }^{16,26}$.

\section{${ }^{1} H$ NMR spectroscopy}

The high frequency region of the ${ }^{1} \mathrm{H}$ NMR spectra shows the chemical shifts for pyrrole hydrogens $(\mathrm{H} \beta)$ and these data were used to characterise the porphyrins. Table 3 shows the chemical shifts and the multiplicities of the signals .

The chemical shifts ( $\delta 8.69 \mathrm{br}$ s) for $\mathrm{H} \beta$ hydrogens (close to the nitrophenyl groups) of $\mathbf{5}$, are at lower frequency than the $\mathrm{H} \beta$ hydrogens (close to the carboxyphenyl groups) of 4 ( $\delta 8.88 \mathrm{br} \mathrm{s})$. This effect is caused by the electron withdrawing effect of the ortho-nitro groups on the phenyl ring, which leads to less deprotection by the anisotropy effect on these $\beta$-pyrrole hydrogens.

For 1, one signal (multiplet, $\delta 8.78-8.83$ ) was observed for $\mathrm{H} \beta$ hydrogens between the carboxyphenyl substituents (Hc, Figure 3) and two signals (doublets) for the other $\mathrm{H} \beta$ hydrogens. The latter arise from hydrogens $\mathrm{Ha}$, which are close to the nitrophenyl group $(\delta 8.69)$; and the former from $\mathrm{Hb}(\delta 8.80)$ next to the carboxyphenyl group (Figure 3$)$. The chemical shift differences for hydrogens $\mathrm{Ha}$ and $\mathrm{Hb}$ reflect the difference in the electron current ring, which induces different anisotropic effects on them. However, for hydrogens $\mathrm{Hc}$, we expected to see a singlet and not a multiplet ${ }^{27}$. This is probably because the molecular aggregation leads to a non-equivalency between hydrogens Hc. Unfortunately, the N-H pyrrole hydrogens were not observed for this compound because the NMR 
Table 3. Chemical shifts ( $\delta$ in ppm) and coupling constants $(J$ in Hz) for $\mathrm{H} \beta$-pyrrole and $\mathrm{N}-\mathrm{H}$ hydrogens for the nitro- and carboxy-phenyl substituted porphyrins.

\begin{tabular}{cccc}
\hline Porphyrin & $\delta$, ppm & $\delta$, ppm & $\delta$, ppm \\
& N-H pyrrolic & $\mathrm{H} \beta-$ carboxy & $\mathrm{H}-$ nitro \\
\hline $\mathbf{5}^{\text {a }}$ & $-2.62 \mathrm{~s}(2 \mathrm{H})$ & - & $8.69 \mathrm{br} \mathrm{s}(8 \mathrm{H})$ \\
$\mathbf{3}^{\mathrm{a}}$ & $-2.68 \mathrm{~s}(2 \mathrm{H})$ & $8.87-8.80 \mathrm{~m}(2 \mathrm{H})$ & $8.75-8.65 \mathrm{~m}(6 \mathrm{H})$ \\
$\mathbf{2}^{\mathrm{a}}$ & $-2.76 \mathrm{~s}(2 \mathrm{H})$ & $8.8-8.84 \mathrm{~m}(4 \mathrm{H})$ & $8.74-8.71 \mathrm{~m}(4 \mathrm{H})$ \\
$\mathbf{1}^{\mathrm{b}}$ & - & $8.83-8.78 \mathrm{~m}(4 \mathrm{H}) 8.80 \mathrm{~d}(\mathrm{~J} 4.6 \mathrm{~Hz})(2 \mathrm{H})$ & $8.69 \mathrm{~d}(J 4.6 \mathrm{~Hz})(2 \mathrm{H})$ \\
$\mathbf{4}^{\mathrm{b}}$ & - & $8.88 \mathrm{br} \mathrm{s}(8 \mathrm{H})$ & - \\
\hline
\end{tabular}

ain $\mathrm{CD}_{2} \mathrm{Cl}_{2} ;$ bin $\mathrm{CD}_{3} \mathrm{OD}$

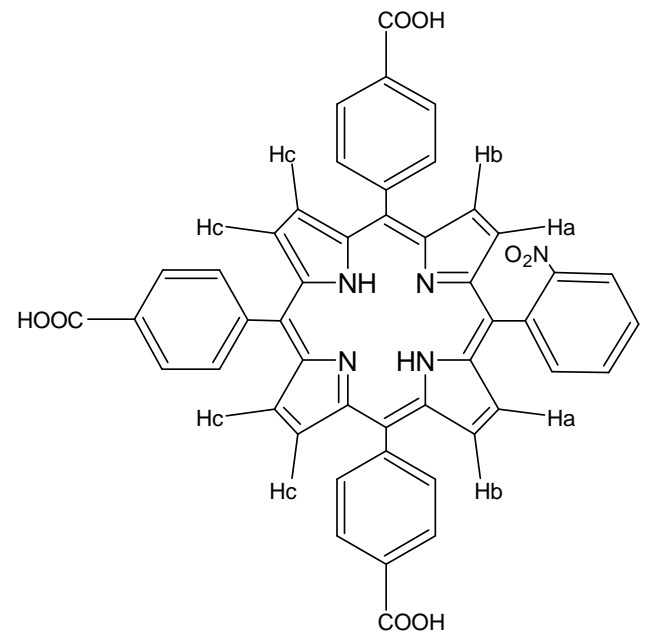

Figure 3. Different $\beta$-pyrrole hydrogens of 5-mono(2-nitrophenyl),10,15,20-tris(4-carboxyphenyl) porphyrin, 1 .

spectrum was obtained in methanol d-4 since this porphyrin is insoluble in dichloromethane. Integration of the areas corresponding to $\mathrm{H} \beta$ (close to carboxy) and $\mathrm{H} \beta$ (close to nitro) hydrogens of $\mathbf{3}, \mathbf{2}$ and $\mathbf{1}$ gave the expected $3: 1,2: 2$ and 1:3 $\left(\mathrm{H}_{\beta}-\mathrm{NO}_{2} / \mathrm{H}_{\beta}-\mathrm{COOH}\right)$ ratios, respectively. For $\mathbf{2}, \mathbf{1}$ and 4 we can also observe a broad hump above the signal corresponding to hydrogens $\mathrm{H} \beta$ (close to nitro) and $\mathrm{H} \beta$ (close to carboxy), which we again suppose are due to intermolecular aggregation. It is well known that porphyrins bearing carboxylic groups can aggregate through hydrogen bonds and also the polar nitro substituent can act as a proton acceptor in hydrogen bonds ${ }^{24}$. The aggregation was indicated also by infrared spectra, which show broad signals corresponding to the carboxyl group.

The chemical shifts of the N-H hydrogens in the centre of the porphyrin are also affected by the number of nitrophenyl groups. Increasing the number of nitro groups leads to the expected high frequency shift of the $\mathrm{N}-\mathrm{H}$ signal. In the region of the phenyl hydrogens the multiplet signals overlap makes the assignments difficult.

\section{Electrochemical characterization}

The electrochemical reduction of free base and iron ortho - nitro and para-carboxy substituted porphyrins was studied both on a glassy carbon electrode and a mercury electrode by cyclic voltammetry and differential pulse polarography, respectively, in $\mathrm{CH}_{2} \mathrm{Cl}_{2} ; 0.1 \mathrm{~mol} \mathrm{dm}^{-3}$ tetran-butylammonium tetraphenylborate (TBATFB).

The electroreduction of the free bases 5,10,15,20(tetraphenyl)porphyrin (6) and tetrakis(o-nitrophenyl) porphyrin (5) and the corresponding iron porphyrins, 6$\mathbf{F e}, 5-\mathbf{F e}$, were also investigated in order to understand the influence of substituents on the electrochemical behaviour of these compounds and for comparison purposes. The free base porphyrins 1, 4 and corresponding iron porphyrins were not investigated by this technique due to their insolubility in dichloromethane which was used as solvent in these studies.

The voltammetric reduction of $\mathbf{6}$ has two characteristic reversible one-electron transfer reactions (Figure 4, Table 4) as judged by wave analysis of ip/ $v^{1 / 2}=$ constant, Epa$\mathrm{Epc}=59 \mathrm{mV}$ and ipa/ipc $=0.9-1.0$ for $v($ scan rate $)=$ $10-2000 \mathrm{mV} \mathrm{s}^{-1}$. These reductions correspond to the production of $\pi$-anion and di-anion radicals as well established in literature ${ }^{28}$. The cyclic voltammograms for nitro-substituted compounds, 2 (Figure 5), $\mathbf{3}$ and $\mathbf{5}$, exhibit two reduction processes at very close potentials (Table 4). Only one anodic peak associated with the reoxidation of product generated in the second reduction step is seen on the reverse scan, but the ipa/ipc ratio is always smaller than one. In addition, both peak potentials show cathodic shifting as a function of scan rate increasing, indicating that nitro-substituted compounds follow a reduction mechanism involving chemical reactions subsequent to the electron transfer ${ }^{29}$. In general, all nitro-substituted free base porphyrins are easier to reduce relative to the parent unsubstituted porphyrin (see Table 4).

A comparison of the electrochemical behaviour with other reported data ${ }^{30,31}$ leads us to suppose that the redox reactions of the nitro-porphyrins reported here also involve the porphyrin $\pi$-ring system. Considering the predominant effect of the nitro groups on the electrochemical properties, all results were analysed as a function of the number of these groups. 


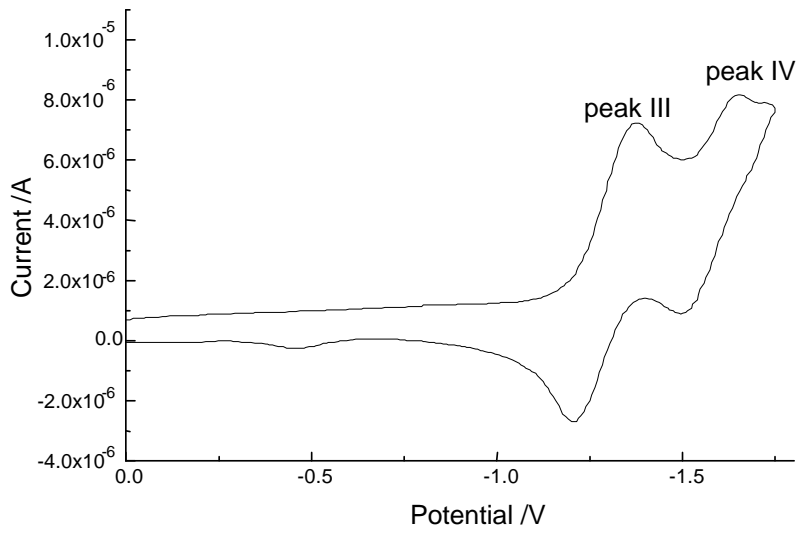

Figure 4. Cyclic voltammograms of 6 in $\mathrm{CH}_{2} \mathrm{Cl}_{2}, 0.1 \mathrm{~mol} \mathrm{dm}^{-3}$ TBATFB. Scan rate $=0.1 \mathrm{~V} \mathrm{~s}^{-1}$

Table 4. Electrochemical data of tetraarylporphyrins on a glassy carbon electrode in $\mathrm{CH}_{2} \mathrm{Cl}_{2}, 0.1 \mathrm{~mol} \mathrm{dm}^{-3}$ TBATFB. $v=100 \mathrm{mV} \mathrm{s}^{-1}$

\begin{tabular}{ccccc}
\hline Compound & \multicolumn{2}{c}{$\begin{array}{c}\text { Iron reduction } \\
\text { potential }\end{array}$} & \multicolumn{2}{c}{$\begin{array}{c}\text { Ring reduction } \\
\text { potential }(\mathrm{V})\end{array}$} \\
\hline & Peak I & Peak II & Peak III & Peak IV \\
$\mathbf{6}$ & - & - & -1.37 & -1.61 \\
$\mathbf{6 - F e}$ & -0.34 & -1.16 & -1.72 & -1.90 \\
$\mathbf{2}$ & - & - & -1.17 & -1.27 \\
$\mathbf{2}-\mathbf{F e}$ & -0.29 & -0.88 & -1.18 & -1.33 \\
$\mathbf{3}$ & - & - & -1.11 & -1.44 \\
$\mathbf{3 - F e}$ & -0.26 & -0.83 & -1.04 & -1.47 \\
$\mathbf{5}$ & - & - & -0.91 & -1.28 \\
$\mathbf{5 - F e}$ & -0.21 & -0.57 & -1.03 & -1.17 \\
\hline
\end{tabular}

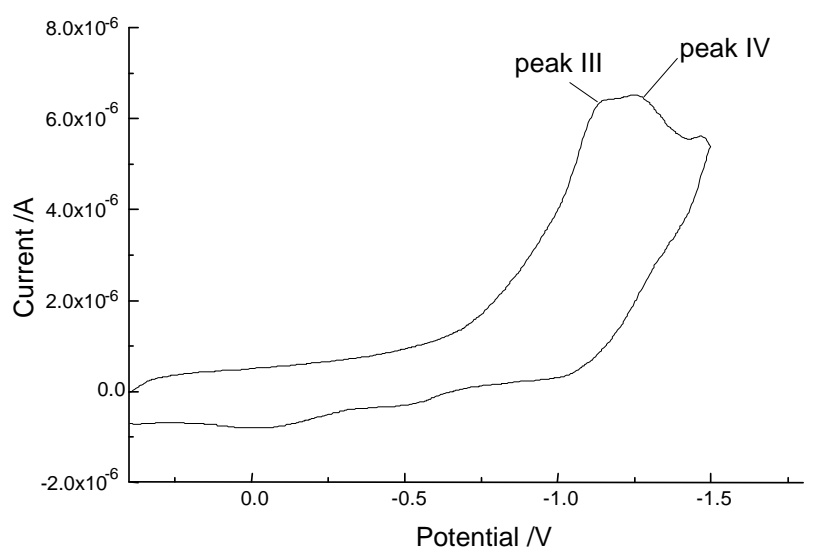

Figure 5. Cyclic voltammograms of 2 in $\mathrm{CH}_{2} \mathrm{Cl}_{2}, 0.1 \mathrm{~mol} \mathrm{dm}-3$ TBATFB. Scan rate $=0.1 \mathrm{~V} \mathrm{~s}^{-1}$

In order to confirm these results, differential pulse polarographic experiments were carried out with the aim to improve wave separation. The same trends are observed in the polarographic behaviour of these compounds, as shown in Table 5. Differential pulse polarograms show well defined reduction waves and the corresponding peak potentials indicate that the reductions are easier, increasing the number of nitro groups on the porphyrin ring. Although the electrochemical behaviour in both electrode systems was similar, a negative shifting in the reduction steps was noticed as compared to that obtained with a glassy carbon electrode, indicating that the nature of the electrode material affects the reduction process.

Table 5. Substituent effect on the reduction potential of tetraarylporphyrins on a mercury electrode (differential pulse polarography) in $\mathrm{CH}_{2} \mathrm{Cl}_{2}, 0.1 \mathrm{~mol} \mathrm{dm}^{-3}$ TBATFB.

\begin{tabular}{ccccc}
\hline Compound & \multicolumn{2}{c}{$\begin{array}{c}\text { Iron reduction } \\
\text { potential }\end{array}$} & \multicolumn{2}{c}{$\begin{array}{c}\text { Ring reduction } \\
\text { potential }(\mathrm{V})\end{array}$} \\
& Peak I & Peak II & Peak III & Peak IV \\
6 & - & - & -0.90 & -1.32 \\
6-Fe & -0.53 & -0.84 & -0.99 & -1.43 \\
$\mathbf{2}$ & - & - & -0.82 & -1.23 \\
2-Fe & -0.24 & -0.62 & -0.84 & -1.33 \\
$\mathbf{3}$ & - & - & -0.68 & -1.13 \\
$\mathbf{3 - F e}$ & -0.26 & -0.60 & -0.75 & -1.15 \\
$\mathbf{5}$ & - & - & -0.60 & -1.06 \\
$\mathbf{5 - F e}$ & -0.19 & -0.46 & -0.65 & -1.14 \\
\hline
\end{tabular}

A typical cyclic voltammogram obtained for nitro substituted iron(III) porphyrins is shown in Figure 6 and compared to that for $\mathbf{6 - F e}$ obtained under the same conditions (Figure 7). All potential values obtained from voltammetric reduction of the iron porphyrins are shown in Table 4. As expected, the compounds containing the metal centre show two extra peaks at less negative potentials than that observed for reduction of the free base porphyrins. These peaks were assigned to the successive reduction of the iron (III)-iron(II) and iron (II)-iron (I) couples in the porphyrin complex ${ }^{32,33}$. However, the cyclic voltammograms are significantly changed in morphology and potential magnitude as the number of nitro groups is increased in the macrocycle.

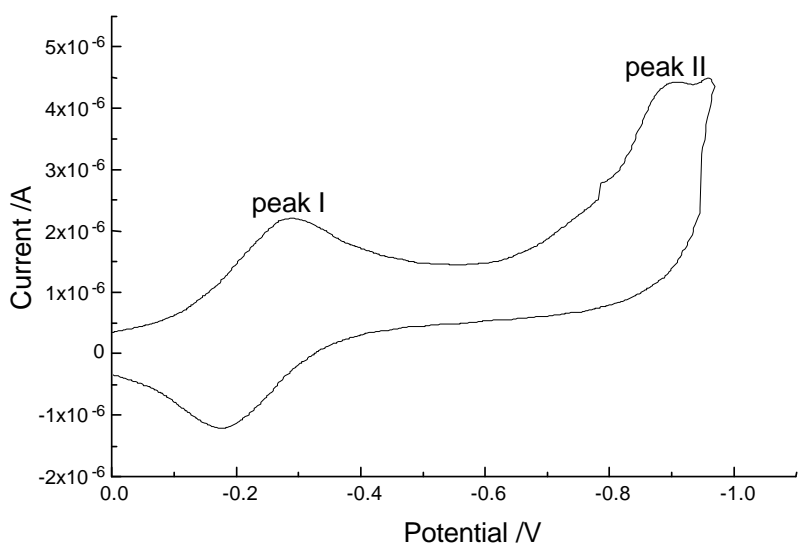

Figure 6. Cyclic voltammograms of 2-Fe in $\mathrm{CH}_{2} \mathrm{Cl}_{2}, 0.1 \mathrm{~mol} \mathrm{dm}-3$ TBATFB. Scan rate $=0.1 \mathrm{~V} \mathrm{~s}^{-1}$

All investigated $\mathrm{FeP}$ undergo a reduction process involving a reversible one electron transfer of the metal 


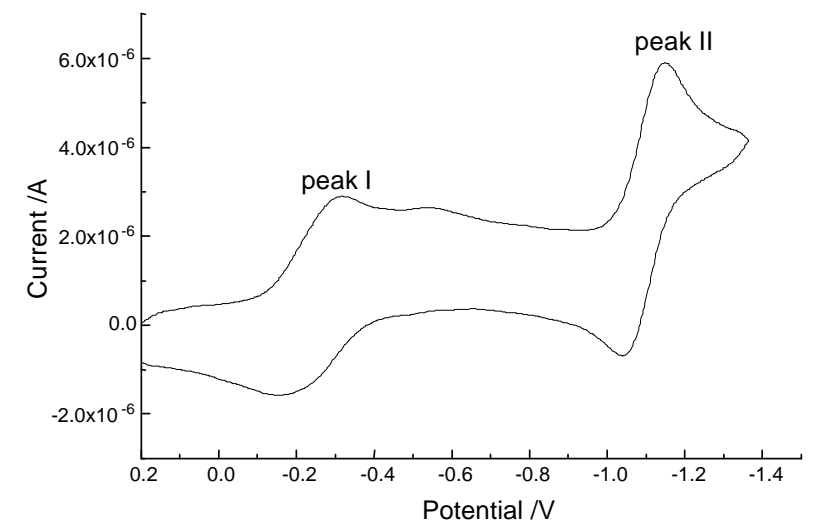

Figure 7. Cyclic voltammograms of 6-Fe in $\mathrm{CH}_{2} \mathrm{Cl}_{2}, 0.1 \mathrm{~mol} \mathrm{dm}^{-3}$ TBATFB. Scan rate $=0.1 \mathrm{~V} \mathrm{~s}^{-1}$

centre to yield $\mathrm{Fe}$ (II), as demonstrated by analysis of the scan rate influence, which shows typical virtually constant values of the $\mathrm{ip} / \mathrm{v}^{1 / 2}$ ratio and $\mathrm{E}_{\mathrm{pa}}-\mathrm{E}_{\mathrm{pc}}$ values always around $60 \mathrm{mV}$. Concomitantly, the peak potential shifts to less negative potential for FeP upon going from 6-Fe to 2-Fe, 3-Fe and then to $\mathbf{5 - F e}$, increasing the number of nitro groups in the macrocycle. The results are confirmed by polarographic techniques, as shown by peak potentials obtained at the mercury electrode (Table 5).

The metal centre second reduction process in the 6-Fe also shows a characteristic reversible reduction involving one electron transfer. Nevertheless, the three nitro derivatives investigated exhibit cyclic voltammograms with the second reduction peak at less negative potential than that required for reduction of the iron(II)-iron(I) couple in 6-Fe. The difference between the first and second reduction potentials decreases as the number of nitro substituents increases. These data may indicate that the second reduction potential is markedly more sensitive to changes in the electronic nature of the porphyrin macrocycle. The cathodic shift of the peak potential could be interpreted as an increased interaction of the iron(II) with the porphyrin ring. The absence of an anodic peak on the reverse potential scan at a slow scan rate indicates that the second reduction process is complicated by fast chemical reactions which probably consume the generated product, assigned as the iron(I) porphyrin complex, under these conditions. This chemical reaction could be the loss or exchange of the axial ligand ${ }^{34}$ or self protonation of the porphyrin ${ }^{35}$.

In addition, the reduction potential of the porphyrin ring system for all iron complexes is shifted up to $690 \mathrm{mV}$ with the introduction of nitro groups, as shown in Tables 4 and 5. As previously observed, the reduction of free base nitro-porphyrins or corresponding iron porphyrins showed the same general trends, indicating that the ring system reduction strongly depends on the number of nitro substituents in the porphyrin macrocyle.

In conclusion, our findings suggest that the electronwithdrawing $\mathrm{NO}_{2}$ groups decrease the electron density in both metal centre and conjugated porphyrin $\pi$-ring system and this leads to easier reduction. On the other hand, the stability of the product electrochemically generated by the reduction of the $\mathrm{Fe}$ (II)- $\mathrm{Fe}$ (I) couple is decreased for the nitro-substituted porphyrins investigated in this study. Further work is now in progress in our laboratory in order to clarify the reduction mechanism of these compounds.

\section{Conclusions}

Despite great difficulties in working with ionic porphyrins due to aggregation, we have synthesized, isolated and characterised a new series of porphyrins containing mixed substituents, nitro and carboxy, in the meso-phenyl rings, with estimated overall porphyrin yield as high as $60 \%$. We have demonstrated that it is possible to optimise the benzaldehyde molar ratio in order to obtain fewer porphyrin isomers and higher concentrations of the desired porphyrins, which facilitates the purification process. These porphyrins are important as possible precursors of systems of the selfassembly type and they are potentially good catalysts due to the versatility of the carboxy and nitro groups which can be used to support them in different materials. Further studies are currently under way to explore the catalytic activities of these compounds in oxidation reactions.

\section{Acknowledgements}

This work was supported by CAPES, CNPq and FAPESP. We thank J. R. Lindsay Smith for discussions and for the FAB MS spectra.

\section{References}

1. (a) Lindsey, J. S. Metalloporphyrins-Catalyzed Oxidations, Montanari, F. and Casella, L. Eds., Academic Publishers, The Netherlands, 1994. (b) Milgron, L.R. The Colours of Life, Oxford University Press, New York, 1997.

2. (a) Ortiz de Montellano, P. R. Cytochrome P450: Structure, Mechanism and Biochemistry, $2^{\text {nd }}$ ed., Plenum Press, New York, 1995. (b) Dolphin, D.; Traylor, T.G.; Xie, L. Y. Acc. Chem. Res.1997, 30, 251.

3. (a) Bonnett, R. Chem. Soc. Rev. 1995, 19. (b) Gaud, O.; Granet, R.; Kaouadji, M.; Krausz, P.; Blais, J. C.; Bolbach, G. Can. J. Chem. 1996, 74, 481. (c) Driaf, K.; Granet, R.; Krausz, P.; Kaouadji, M.; Thomasson, 
F.; Chulia, A. J.; Verneuil, B.; Spiro, M.; Blais, J. C.; Bolbach, G. Can. J. Chem. 1996, 74, 1550.

4. Arimura, T. J. Synthetic Org. Chem. Japan 1997, $55,557$.

5. (a) Lindsey, J. S.; Prathapan, S.; Johnson, J. E.; Wagner, R. W. Tetrahedron 1994, 50, 8941. (b) Drain, C. M.; Nifiatis, F.; Vasenko, A.; Batteas, J. D. Angew. Chem. Int. Ed. 1998, 37, 2344. (c) Vicente, M. G. H.; Cancilla, M. T.; Lebrilla, C. B.; Smith, K. M. Chem. Commun. 1998, 2355. (d) Biemans, H. A. M.; Rowan, A. E.; Verhoeven, A.; Vanoppen, P.; Latterini, L.; Schenning, J.; Meijer, E. W.; Schryver, F. C.; Nolte, R. J. M. J. Am. Chem. Soc. 1998, 120, 11054. (e) Osuka, A.; Shimidzu, H. Angew. Chem. Int. Ed. Engl. 1997, 36, 135.

6. Kaim, W.; Schwederski, B. Bioinorganic Chemistry: Inorganic Elements in the Chemistry of Life, John Wiley \& Sons, Chichester, 1995.

7. Lindsay Smith, J. R. Metalloporphyrins in Catalytic Oxidations, Sheldon, R. A. Ed., Marcel Dekker, New York, 1994.

8. (a) Bedioui, F. Coord. Chem. Rev. 1995, 144, 39. (b) Mansuy, D.; Battioni, P.; Battioni, J. P. Eur. J. Biochem. 1989, 184, 267.

9. (a) Assis, M. D.; Serra, O. A.; Iamamoto, Y. Inorg. Chim. Acta 1991, 187, 109. (b) Assis, M. D.; Mello, A. J. B.; Serra, O. A.; Iamamoto, Y. J. Mol. Catal A: Chemical 1995, 97, 41.

10. Meng, G. G.; James, B. R.; Skov, K. A. Can. J. Chem. 1994, 72, 1894, and references therein.

11. Rocha Gonsalves, A. M. d'A.; Varejão, J. M. T. B.; Pereira, M. M. J. Heterocyclic Chem. 1991, 28, 635.

12. (a) Buchler, J. W.; Kunzel, F. M.; Mayer, U.; Nawra, M. Fresenius J. Anal. Chem. 1994, 348, 371. (b) Herrmann, O.; Medhi, H.; Corsini, A. Can. J. Chem. 1978, 56, 1084.

13. Adler, A. D.; Longo, F. R.; Kampas, F.; Kim, J. J. Inorg. Nucl. Chem. 1970, 32, 2445.

14. (a) Rothemund, P. J. Am. Chem. Soc.1936, 58, 625.

(b) Rothemund, P. J. Am. Chem. Soc. 1939 61, 2912.

15. (a) Lindsey, J. S.; Schreiman, I. C.; Hsu, H. C.; Kearney, P. C.; Marguerettaz, A. M. J. Org. Chem. 1987, 52, 827. (b) Lindsey, J. S.; Wagner, R. W. J. Org. Chem. 1989, $54,828$.

16. Datta-Gupta, N.; Bardos, T. J. J. Heterocyclic Chem. 1966, 3, 495.

17. (a) Bigey, P.; Frau, S.; Lomp, C.; Claparols, C.; Bernadou, J.; Meunier, B. Bull. Soc. Chim. Fr.1996,
13, 679. (b) Assis, M. D.; Lindsay Smith, J. R. J. Chem. Soc., Perkin Trans.II 1998, 2221.

18. Bonar-Law, R. P. J. Org. Chem. 1996, 61, 3623.

19. (a) Grishima, L. E.; Brykina, G. D.; Shpigum, O. A. J. Anal. Chem. 1995, 50, 826. (b) Jensen, J. J. Chromatog. 1963, 10, 236. (c) Chu, T. C. and Chu, E. J. J. Chromatog. 1966, 21, 46.

20. (a) Wilkelman, J. Cancer Research, 1962, 22, 589. (b) J. Wilkeman, J.; Slater, G.; Grossman, J. Cancer Research 1967, 27, 2060.

21. Harada, A.; Shiotsuki, K.; Yamaguchi, H.; Kamachi, M. Inorg. Chem. 1995, 34, 1070.

22. Silverstain, R. M.; Bassier, G. C.; Morril, T. C. Spectrometric Identification of Organic Compounds, John Wiley and Sons, Inc., $3^{\mathrm{a}}$ ed., 1974 .

23. Collman, J. P.; Brauman, J. I.; Doxee, K. M.; Halbert, T. R.; Bunnenberg, E.; Linder, R. E.; Lanar, G. N.; Gaudio, J. D.; Spartalian, K. J. Am. Chem. Soc. 1980, 102, 4182.

24. Kumar, R. K.; Balasubramanian, S.; Goldberg, I. Inorg. Chem. 1998, 37, 541.

25. Bellamy, L. J. The Infrared Spectra of Complex Molecules, John Willey and Sons, New York, 1954, ch. 10.

26. Thomas, D. W.; Martell, A. B. J. Am. Chem. Soc. 1959, $81,5111$.

27. Meng, G. G.; James, B. R.; Skov, K. A. Can. J. Chem. 1994, 72, 1894.

28. Fuhrlop, J. H.; Kadish, K. M.; Davis, D. G. J. Am. Chem. Soc. 1982, 95, 5140.

29. Bard, A. J. Electrochemical Methods, John Willey and Sons, New York, 1980.

30. Giraudeau, A.; Callot, H. J.; Gross, M. Inorg. Chem. 1979, 18, 201.

31. Arao, T.; Maiya, B. G. Polyhedron 1994, 13,1863.

32. Messet, M. J. M.; Shokhirev, N. V.; Enemark, P. D.; Jacobson, S. E.; Walker, F. A. Inorg. Chem. 1996, 35, 5188.

33. Kadish, K. M.; Morrison, M. M.; Constant, L. A.; Dickens, L.; Davis, D. G. J. Am. Chem. Soc.1976, 98, 8337.

34. (a) Bottomley, L. A.; Kadish, K. Inorg. Chem. 1981, 20, 1348. (b) Lexa, D.; Momenteau, M.; Mispeltier, J.; Lhoste, J.M., Bioelectrochem. Bioenerg. 1975, 1,108 .

35. (a) Davis, D. G. in "The Porphyrins", D. Dolphin Ed., v.V, ch. 4, 19. (b) Constant, L. A.; Davis, D. G. Anal. Chem. 1975, 47, 2253.

Received: May 31, 1999

Published on the web: August 31, 2000

FAPESP helped in meeting the publication costs of this article. 